\title{
Mucosal melanoma of the head and neck: a population-based study from Slovenia, 1985-2013
}

\author{
Gaber Plavc ${ }^{1}$, Jasna But-Hadžić ${ }^{1}$ Aleksandar Aničin², Boštjan Lanišnik ${ }^{3}$, Vojislav Didanović ${ }^{4}$ and Primož Strojan ${ }^{1,5^{*}}$
}

\begin{abstract}
Objectives: To assess the incidence and to review experience with the treatment of mucosal melanoma of the head and neck (MMHN) in Slovenia between 1985 and 2013.

Methods: The National Cancer Registry database and clinical records with outcome data of identified patients treated during the period 1985-2013 in Slovenia were reviewed.

Results: In a 29-year period, 61 patients with MMHN were identified, representing $0.5 \%$ of all head and neck malignant tumors and $42 \%$ of all mucosal melanomas in Slovenia. $72 \%$ originated in the sinonasal tract and were predominantly (78 \%) diagnosed as a local disease. Regional metastases at diagnosis were more frequent in patients with oral/oropharyngeal primary (44\%; sinonasal MMHN $11 \%, p=0.006)$. Curative intent treatment was given to 48 (79\%) patients. The overall survival (OS) rates at 2 and 5 years for the whole cohort were $43 \%$ and $18 \%$, respectively, and for the curative intent group $53 \%$ and $24 \%$, respectively. In the latter group, multivariate analyses showed postoperative radiotherapy (PORT) to be predictive for locoregional control (LRC) (hazard ratios [HR] for surgery with PORT vs. surgery alone: 1.0 vs. 3.9, $p=0.037$ ), whereas only the World Health Organization performance status (HR for grade 0 vs. grade 1 vs. grade $>1: 1.0(p=0.022)$ vs. $1.2(p=0.640)$ vs. $7.7(p=0.008)$ ) significantly influenced OS.

Conclusions: MMHN is a rare tumor with a poor prognosis. Combination of surgery and PORT offers the best prospects for LRC but without improvement of OS. Due to potential toxicity of high-dose RT such treatment is indicated in patients in whom LRC outweighs the risks of serious adverse effects.
\end{abstract}

Keywords: Mucosal melanoma, Head and neck cancer, Epidemiology, Therapy, Survival

\section{Introduction}

Mucosal melanoma of the head and neck region (MMHN) was first described by Weber in 1856 and has since been the subject of an increasing number of retrospective studies while its rareness precluded any prospective trials [1]. The yearly incidence of mucosal melanoma is 2.2-2.6 cases per million and approximately half of the cases appear in the upper part of the aerodigestive tract [2-4]. Higher MMHN incidence was reported in Japan and Uganda, although the ratio of MMHN vs. all mucosal

\footnotetext{
* Correspondence: pstrojan@onko-i.si

${ }^{1}$ Department of Radiation Oncology, Institute of Oncology, Ljubljana, Slovenia

${ }^{5}$ Faculty of Medicine, University of Ljubljana, Ljubljana, Slovenia

Full list of author information is available at the end of the article
}

melanomas seems to be the same for Caucasians and the Japanese [5, 6].

Malignant melanomas derive from melanocytes or their precursor cells arising from the neural crest [7]. Contrary to its cutaneous counterpart, strong evidence of environmental risk factors for the development of mucosal melanoma is lacking and the possible role of premalignant lesions remains to be elucidated as well [8]. Diagnosis of pigmented MMHN is usually unambiguous, however, it can be difficult to obtain in amelanotic and ulcerated lesions [9]. Regardless of treatment, overall survival (OS) in MMHN is poor and rarely do 5-year OS rates exceed $30 \%$ [8]. It is generally agreed upon that radical surgical resection of the primary tumor offers the best chance of local control and cure, whereas the role of 
elective neck resection and adjuvant-postoperative radiotherapy (PORT) is not well established [8].

In the present study we sought to describe the incidence of MMHN in Slovenia for the period from 1985 to 2013, to report our experience with these patients, and to assess the significance of previously proposed prognostic factors.

\section{Patients and methods}

\section{Patient and tumor characteristics}

Patients diagnosed from 1985 through 2013 with MMHN in Slovenia were eligible for this nationwide populationbased retrospective study. In total, 61 consecutive patients were identified by the Cancer Registry database, a population-based cancer registry covering the entire Slovenian population since 1950 [10].

Epidemiological and clinical parameters are presented in Table 1. Tumors were most frequently located in the sinonasal tract (SN) (44 patients, $72 \%$ ) with subsites of origin as follows: nasal cavity (33 patients, $54 \%$ ), maxillary sinus (6 patients, $9.8 \%$ ), ethmoid sinus (3 patients, $4.9 \%$ ) and nasopharynx (2 patients, $3.3 \%)$. Sixteen tumors (26\%) originated from the oral cavity (14 patients, $23 \%$ ) and oropharynx (2 patients, $3.3 \%$ ) (OC-OP). One patient presented with $\mathrm{MMHN}$ of the middle ear.

At presentation, localized disease was found in 48 patients $(789 \%)$ with 21 (44 \%) tumors staged as T3, 22 (46 \%) as T4a and $5(10 \%)$ as T4b (UICC TNM, 7th ed.). Twelve patients $(20 \%)$ presented with positive cervical lymph nodes (CLN) and three patients (4.9\%) were diagnosed with distant metastases: one of these patients had lung metastases, while the other two presented with metastatic spread to multiple sites (Table 1). Presenting symptoms and initial diagnostic work-up are summarized in Table 2.

\section{Treatment}

Forty-eight patients $(79 \%)$ were treated with curative intent, nine $(14.8 \%)$ received palliative treatment and four $(6.6 \%)$ had only symptomatic treatment.

\section{Treatment of primary tumor}

In the curative intent group, the first-line therapy was surgery in 37 patients (77\%) and definitive RT in 11 (23\%). There was no statistically significant difference either in TNM stage distribution or in World Health Organization performance status (WHO PS) between these two groups. Surgery was either open (22 patients, $59 \%$ ) or endoscopic (15 patients, $41 \%$ ) with clear margins achieved in 31 cases (84\%). PORT was delivered in $16(43 \%)$ patients, from 20 to 65 days after surgery (median, 45 days) (Table 1). In five cases the indications for adjuvant RT to the primary tumor bed were positive margins of resection, while in the other 11 cases the decision for adjuvant RT was based on SN localization (7 cases), high local disease burden (pT4, seven patients) or regional spread ( $\mathrm{pN}+$, three patients). Six out of 11 primarily irradiated patients had a complete response locally (assessed 8 to 12 weeks after RT by local clinical examination only), four had a partial response and one patient was declared a non-responder. No patient was surgically salvaged, the reasons being an inoperable disease or the patient's general condition being deemed unsuitable for surgery. In the PORT and definitive RT groups the equivalent RT doses to the primary tumor site in 2-Gy fractions $\left(\mathrm{EQD}_{2}, \alpha / \beta=2\right.$ Gy) [11] ranged from 45.0 to 72.0 Gy (median, 60.0 Gy) and from 52.5 to 75.0 Gy (median, $68.8 \mathrm{~Gy}$ ), respectively. RT was delivered using conventional fractionation of five 2.0-3.0 Gy fractions (median, 2.0 Gy) per week in 17 cases, and hypofractionation of 2-3 weekly fractions of 4.0-6.0 Gy (median, $6.0 \mathrm{~Gy}$ ) in 10 cases.

\section{Treatment of neck}

Eight patients had neck dissection, of whom six had clinically palpable CLN; metastatic nodes were found in all six patients. Four of these patients had PORT (45.0-66.0 Gy, median 65.0 Gy) due to $\mathrm{pN}+$ disease (three patients, two with extracapsular tumor spread) and synchronous squamous cell carcinoma of the tongue base spreading to the CLN (1 patient). In patients without neck surgery, CLN were irradiated in six cases, four of them having had bilateral RT (63.0-72.0 Gy, median $70.0 \mathrm{~Gy}$ ). Two of these patients had clinically positive CLN; complete and partial response was clinically recorded after $\mathrm{RT}$ in one patient each.

\section{Radiotherapy technique}

Two-dimensional computer planning, three-dimensional conformal technique (3D-CRT) and intensity-modulated technique (IMRT) were employed in 15 (56 \%), eight (30\%) and three (11\%) patients, respectively, whereas in one patient RT was delivered by direct opposing field (3.7\%). RT was delivered by a $12 \mathrm{MeV}$ electron beam, megavoltage cobalt-60 and 5-10 MV photon beams in one, six and 20 patients, respectively. After the year 2007, 3D-CRT and IMRT were introduced (and cobalt-60 irradiation was abandoned) in all the patients receiving radiotherapy.

\section{Adjuvant systemic therapy}

It was administered to 10 patients treated with curative intent $(21 \%)$. In 6/10 low-dose interferon $\alpha-2 b$ (3 million IU i.m., three times/week for 25-60 weeks) was given after the primary operation, two patients had chemotherapy (vinblastine-lomustine-cisplatin, three cycles; dacarbazine, nine cycles) after RT and two patients were treated with concurrent PORT and low-dose interferon $\alpha-2 b$. 
Table 1 Epidemiological and clinical parameters of 61 patients with MMHN diagnosed in Slovenia, 1985-2013

\begin{tabular}{|c|c|c|c|c|}
\hline \multirow[t]{2}{*}{ Characteristic } & All cases & Sinonasal tract & Oral cavity \& oropharynx & \multirow[t]{2}{*}{$p$-value } \\
\hline & $N=61(\%)$ & $N=44(\%)$ & $N=16(\%)$ & \\
\hline \multicolumn{5}{|l|}{ Age at diagnosis (years) } \\
\hline Median & 75.5 & 77.0 & 68.2 & \multirow[t]{2}{*}{0.059} \\
\hline Range & $25.9-91.8$ & $40.0-91.8$ & $25.9-87.3$ & \\
\hline \multicolumn{5}{|l|}{ Sex } \\
\hline Male & $32(53)$ & $20(46)$ & $11(69)$ & \multirow[t]{2}{*}{0.110} \\
\hline Female & $29(48)$ & $24(55)$ & $5(31)$ & \\
\hline \multicolumn{5}{|l|}{ PS WHO } \\
\hline Grade 0 & $29(48)$ & $18(41)$ & $10(63)$ & \multirow[t]{3}{*}{0.276} \\
\hline Grade 1 & $23(38)$ & $18(41)$ & $5(31)$ & \\
\hline Grade $>1$ & $9(15)$ & $8(18)$ & $1(6.3)$ & \\
\hline \multicolumn{5}{|c|}{ Duration of symptoms (months) } \\
\hline Median & 2.0 & 2.0 & 1.0 & \multirow[t]{2}{*}{0.554} \\
\hline Range & $0.0-12.0$ & $0.0-12.0$ & $0.0-12.0$ & \\
\hline \multicolumn{5}{|l|}{ Tumor pigmentation } \\
\hline Yes & $36(59)$ & $23(52)$ & $13(81)$ & \multirow[t]{3}{*}{0.165} \\
\hline No & $13(21)$ & $11(25)$ & $2(13)$ & \\
\hline Unknown & $12(20)$ & $10(237)$ & $1(6.3)$ & \\
\hline \multicolumn{5}{|l|}{ Overall stage } \\
\hline 1 & $48(79)$ & $38(86)$ & $9(56)$ & \multirow[t]{3}{*}{0.029} \\
\hline 2 & $10(16)$ & $4(9.1)$ & $6(38)$ & \\
\hline 3 & $3(4.9)$ & $2(4.5)$ & $1(6.3)$ & \\
\hline \multicolumn{5}{|l|}{ TNM stage } \\
\hline III & $21(34)$ & $16(36)$ & $4(25)$ & \multirow[t]{4}{*}{0.203} \\
\hline IVA & $30(49)$ & $19(43)$ & $11(69)$ & \\
\hline IVB & $7(12)$ & $7(16)$ & $0(0.0)$ & \\
\hline IVC & $3(4.9)$ & $2(4.5)$ & $1(6.3)$ & \\
\hline \multicolumn{5}{|l|}{ Treatment intent } \\
\hline Curative & $48(79)$ & $33(75)$ & $14(88)$ & \multirow[t]{2}{*}{0.299} \\
\hline Palliative & $13(21)$ & $11(25)$ & $2(13)$ & \\
\hline \multicolumn{5}{|l|}{ Surgery } \\
\hline No & $22(36)$ & $20(46)$ & $2(13)$ & \multirow[t]{2}{*}{0.019} \\
\hline Yes & $39(64)$ & $24(55)$ & $14(88)$ & \\
\hline Open surgery & $24(62)$ & $10(42)$ & $13(93)$ & \multirow[t]{2}{*}{0.002} \\
\hline Endoscopic surgery & $15(39)$ & $14(58)$ & $1(7.1)$ & \\
\hline \multicolumn{5}{|l|}{ Radiotherapy } \\
\hline No & $28(46)$ & $21(48)$ & $7(44)$ & \multirow[t]{2}{*}{0.785} \\
\hline Yes & $33(54)$ & $23(52)$ & $9(56)$ & \\
\hline Definitive & $11(33)$ & $9(39)$ & $2(22)$ & 0.066 \\
\hline Postoperative & $16(49)$ & $8(35)$ & $7(78)$ & \\
\hline Palliative & $6(18)$ & $6(26)$ & $0(0.0)$ & \\
\hline Systemic therapy & & & & \\
\hline Yes & $13(21)$ & $10(23)$ & $3(19)$ & 0.741 \\
\hline No & $48(79)$ & $34(77)$ & $13(81)$ & \\
\hline 2 -year overall survival ${ }^{a}$ & $43(30-55)$ & $40(26-55)$ & $54(29-79)$ & 0.548 \\
\hline 5 -year overall survival ${ }^{a}$ & $18(7.8-29)$ & $20(7.4-32)$ & $15(0.0-35)$ & 0.548 \\
\hline
\end{tabular}


Table 2 Presenting symptoms and initial diagnostic work-up

\begin{tabular}{|c|c|}
\hline Presenting symptoms & No. of patients (\%) \\
\hline Epistaxis & $20(33)$ \\
\hline Evident mass or swelling & $18(30)$ \\
\hline Nasal obstruction & $17(28)$ \\
\hline Pain & $3(4.9)$ \\
\hline Regional non-nasal bleeding & $2(3.3)$ \\
\hline Hearing impairment & $2(3.3)$ \\
\hline Headache & $1(1.6)$ \\
\hline Dysphagia & $1(1.6)$ \\
\hline Signs of metastatic disease & $1(1.6)$ \\
\hline No symptoms reported & $17(28)$ \\
\hline \multicolumn{2}{|l|}{ Duration of symptoms (months) } \\
\hline Range & $0.0-12.0$ \\
\hline Median & 2.0 \\
\hline \multicolumn{2}{|l|}{ Diagnostic work-up } \\
\hline \multicolumn{2}{|l|}{ Local tumor extension } \\
\hline $\mathrm{CT}$ & $31(51)$ \\
\hline Endoscopy & $19(31)$ \\
\hline MRI & $5(8.2)$ \\
\hline Sinus X-ray & $5(8.2)$ \\
\hline Clinical examination only & $16(26)$ \\
\hline \multicolumn{2}{|l|}{ Regional node involvement } \\
\hline US & $31(51)$ \\
\hline $\mathrm{CT}$ & $2(3.3)$ \\
\hline MRI & $1(1.6)$ \\
\hline Clinical examination only & $29(48)$ \\
\hline \multicolumn{2}{|l|}{ Distant metastatic spread } \\
\hline Chest X-ray & $45(74)$ \\
\hline Abdominal US & $31(51)$ \\
\hline Bone scan & $4(6.6)$ \\
\hline Thoracic CT & $3(4.9)$ \\
\hline PET-CT & $3(4.9)$ \\
\hline Head CT & $1(1.6)$ \\
\hline Clinical examination only & $12(20)$ \\
\hline
\end{tabular}

CT Computer tomography, MRI Magnetic resonance imaging, US Ultrasonography, PET Positron emission tomography

\section{Palliative treatment}

It was offered to nine patients and consisted of either local excision or debulking of the primary tumor (2 patients), palliative RT (6 patients, EQD 2 24-68 Gy, median $53.6 \mathrm{~Gy})$ or systemic therapy only (1 patient).

\section{Statistical analyses}

The study protocol was approved by the Protocol Review Board of the Institute of Oncology Ljubljana (ERID-KESOPKR/47).
The survival times were calculated from the start of treatment and were censored at the close-out date (February 15th 2015). The end points considered were local control (LC), regional control (RC), locoregional control (LRC), distant metastasis-free survival (DMFS), and OS (death from any cause considered as an event). The Kaplan-Meier method was used for univariate analysis of survival estimates and the differences between potential prognostic groups were tested by a log-rank test with $95 \%$ confidence intervals (CI) reported. The hazard ratio (HR) calculations and multivariate analysis of significant prognostic factors from univariate analysis were performed by the Cox proportional hazard regression model. The number of covariates to be included in the multivariate analysis was determined according to Peduzzi et al. recommending 10 events per variable [12]. All statistical tests were 2 -sided and a $p$-value $<0.05$ was considered significant.

\section{Results \\ Epidemiology}

In the 29-year period from 1985 to 2013, MMHN represented $0.5 \%$ of all head and neck malignancies, $0.8 \%$ of all melanomas, $4.4 \%$ of all melanomas in the head and neck region and $42 \%$ of all mucosal melanomas in Slovenia.

\section{Follow-up}

The length of the follow-up period for all 61 patients ranged from 0.9 to 190.2 months (median, 16.5 months), and 22.5 months (range, 0.9-190.2 months) and 8.8 months (range, 1.6-25.7 months) for those treated with curative and palliative intent, respectively.

\section{Patterns of failure}

Out of 48 patients treated with curative intent, 15 (31\%) patients eventually failed locally. The median time to local recurrence was 15.4 months (range, 3.4-69.2 months) and to regional recurrence, diagnosed in eight patients (17\%; $5 / 8$ patients had no treatment to the neck) 7.7 months (range, 3.4-106.3 months) after the start of the treatment.

The 2- and 5-year LRC rates were $52 \%$ (95\% CI 36-69) and $27 \%$ (95\% CI 7.6-46), respectively. Within the group of operated patients the improvement in LRC with the addition of PORT was significant $(p=0.019)$ with LRC at 2 years in operated-only patients and those with PORT being $43 \%$ (95 \% CI 18-68) and 84 \% (95\% CI 64-100), respectively, and at 5 years $18 \%$ (95\% CI 0-40) and $67 \%$ (95\% CI 33-100), respectively.

Systemic disease eventually developed in 24 (50\%) patients 0.9 to 145.5 months after therapy (median, 11.8 months; $95 \%$ CI 4.2-23). The DMFS rates at 2 and 5 years were $58 \%$ (95\% CI 42-73) and $40 \%(95 \%$ CI 22-57). 
Several prognostic factors were confirmed to be statistically significant on univariate analysis in terms of influencing the LC, LRC, and DMFS (Table 3). In multivariate analysis, only treatment modality appeared significant for predicting LC (Fig. 1, Table 4).

\section{Survival and prognosis}

In curative intent treatment group, salvage therapy was offered to 23 out of 30 patients (77\%) with recurrent disease, of whom nine were treated more than once. At the close-out date, 38 patients (79 \%) had died of MMHN, five $(10 \%)$ were alive and free of MMHN, and four had died of other causes (with persistent MMHN occurring in one patient). For one patient the vital status was unknown.
The OS ranged from 0.9 to 190.2 months (median, 25.4 months; $95 \%$ CI 2.5-48). The OS rates at 2 and 5 years were $53 \%$ (95 \% CI 39-67) and $24 \%$ (95\% CI 11-36), respectively. Univariate analysis showed a significant impact of age $(p=0.036)$, PS WHO $(p<0.001)$ and systemic therapy $(p=0.011)$ on OS (Table 3$)$. Besides these, treatment modality as a clinically relevant factor with marginal significance $(p=0.074)$ in univariate analysis was also introduced into the Cox multivariate model. However, only PS WHO was retained in the model (Table 4).

For the whole cohort of 61 patients, the OS rates at 2 and 5 years were $43 \%$ (95\% CI 30-55) and $18 \%$ (95\% CI 7.8-29), respectively.

Table 3 Univariate analysis

\begin{tabular}{|c|c|c|c|c|c|}
\hline \multirow[t]{2}{*}{ Prognostic factor } & \multicolumn{5}{|c|}{ Outcome ( $p$-value $)^{*}$} \\
\hline & $\overline{L C}$ & LRC & DMFS & DSS & OS \\
\hline \multicolumn{6}{|l|}{ Age (years) } \\
\hline$<65$ vs. $>65$ & 0.188 & 0.135 & 0.083 & 0.074 & 0.036 \\
\hline \multicolumn{6}{|l|}{ Sex } \\
\hline Male vs. Female & 0.674 & 0.241 & 0.425 & 0.276 & 0.189 \\
\hline \multicolumn{6}{|l|}{ Performance status (WHO) } \\
\hline 0 vs. 1 vs. $2+3+4$ & 0.034 & 0.095 & 0.860 & $<0.001$ & $<0.001$ \\
\hline \multicolumn{6}{|l|}{ Site } \\
\hline SN vs. OC-OP & 0.125 & 0.056 & 0.291 & 0.581 & 0.768 \\
\hline \multicolumn{6}{|l|}{ Pigmented lesion } \\
\hline Yes vs. No & 0.888 & 0.953 & 0.157 & 0.329 & 0.246 \\
\hline \multicolumn{6}{|l|}{ T-stage } \\
\hline T3 vs. T4A/B & 0.752 & 0.931 & 0.643 & 0.291 & 0.226 \\
\hline \multicolumn{6}{|l|}{ N-stage } \\
\hline No vs. N+ & 0.612 & 0.650 & 0.892 & 0.741 & 0.742 \\
\hline \multicolumn{6}{|l|}{ TNM-stage } \\
\hline III vs. IVA/B & 0.595 & 0.708 & 0.807 & 0.382 & 0.315 \\
\hline \multicolumn{6}{|l|}{ Year of first treatment } \\
\hline 1985-2007 vs. 2008-2013 & 0.926 & 0.286 & 0.860 & 0.777 & 0.916 \\
\hline \multicolumn{6}{|l|}{ Treatment modality } \\
\hline Surgery vs. RT vs. surgery + PORT & $<0.001$ & $<0.001$ & 0.796 & 0.111 & 0.074 \\
\hline \multicolumn{6}{|l|}{ Systemic therapy } \\
\hline Yes vs. No & 0.858 & 0.376 & 0.036 & 0.022 & 0.011 \\
\hline \multicolumn{6}{|l|}{ Failure of local control } \\
\hline Yes vs. No & NA & NA & 0.994 & 0.802 & 0.905 \\
\hline \multicolumn{6}{|l|}{ Failure of regional control } \\
\hline Yes vs. No & 0.720 & NA & 0.498 & 0.636 & 0.472 \\
\hline \multicolumn{6}{|l|}{ Failure of distant control } \\
\hline Yes vs. No & 0.741 & 0.434 & NA & 0.088 & 0.234 \\
\hline
\end{tabular}

*Regional control was not used in Kaplan-Meier calculations due to low number of events $(N=8)$. LC Local control, RC Regional control, LRC Locoregional control, DMFS Distant metastasis-free survival; DSS Disease-specific survival, OS Overall survival, WHO World Health Organization, SN Sinonasal, OC-OP Oral cavity/oropharynx, RT Radiotherapy, PORT Postoperative radiotherapy, NA Not applicable 

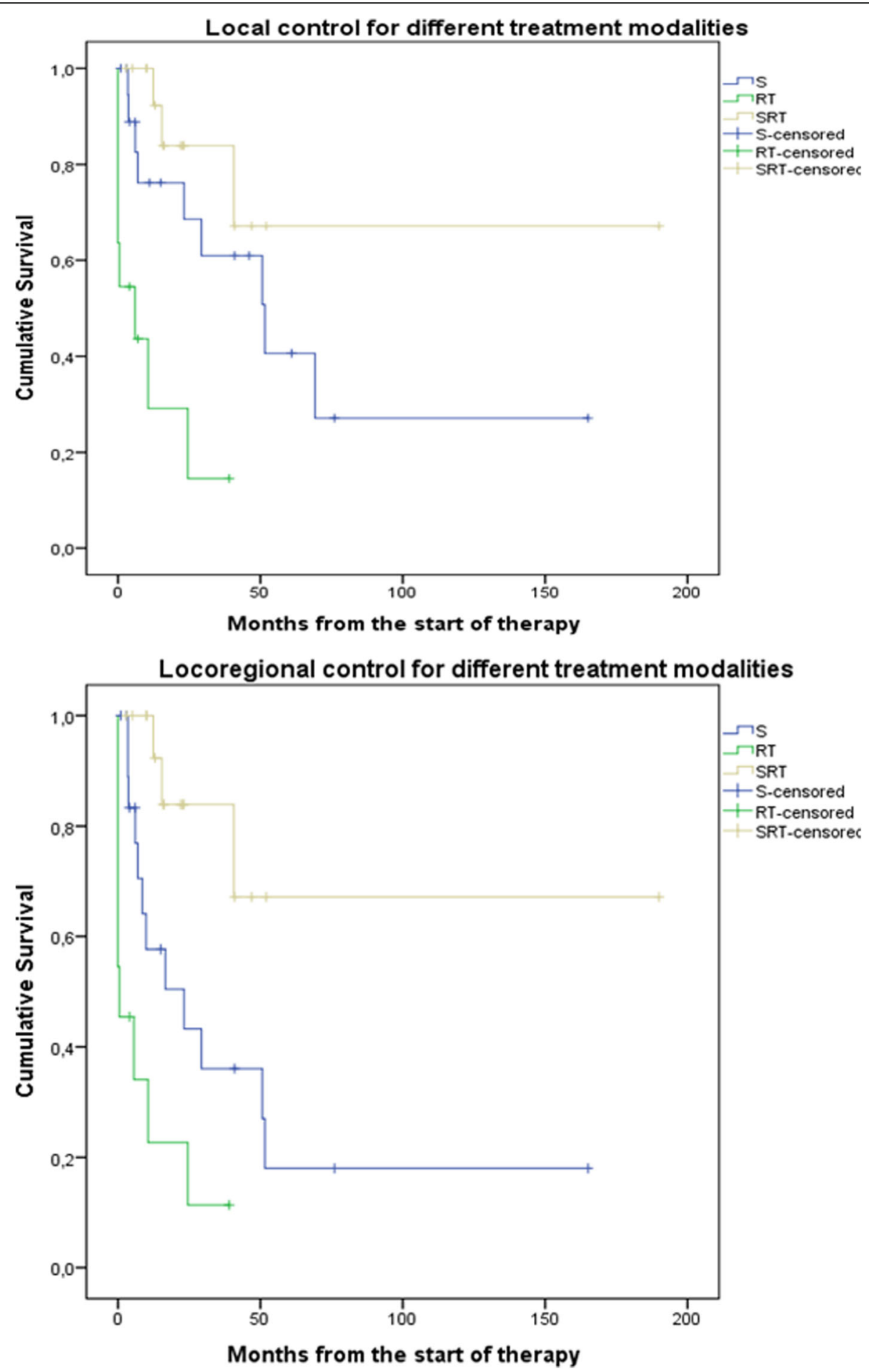

Fig. 1 Impact of treatment modalities on local and locoregional control. S - surgery, RT - radiotherapy, SRT - surgery and postoperative radiotherapy

\section{Long-term survivors}

Nine out of 48 patients (19\%; six females and three males, from $28.6-77.8$ years of age, median 75.5 years) survived for 5 years or more after being diagnosed with MMHN, of whom three lived 12.1, 13.8 and 15.9 years after diagnosis. The origin of primary tumors was the nasal cavity in seven cases and oral cavity in two cases. Primary tumor stage at diagnosis was T3 in five and T4a in four cases; one patient was presented with regional metastases. All patients had up-front surgery 
Table 4 Multivariate analysis

\begin{tabular}{|c|c|c|c|c|c|c|c|c|}
\hline \multirow{2}{*}{$\begin{array}{l}\text { Prognostic } \\
\text { factor }^{{ }^{a}}\end{array}$} & \multicolumn{2}{|l|}{ LC } & \multicolumn{2}{|l|}{$\underline{L R C}$} & \multicolumn{2}{|l|}{ DMFS } & \multicolumn{2}{|l|}{ OS } \\
\hline & $\mathrm{HR}(95 \% \mathrm{Cl})$ & $\overline{p \text {-value }}$ & HR (95 \% Cl) & $\overline{p \text {-value }}$ & $\mathrm{HR}(95 \% \mathrm{Cl})$ & $\overline{p \text {-value }}$ & $\mathrm{HR}(95 \% \mathrm{Cl})$ & $p$-value \\
\hline \multicolumn{9}{|l|}{ Age (years) } \\
\hline$<65$ & $\mathrm{NI}$ & & $\mathrm{NI}$ & & 1.0 & & 1.0 & \\
\hline$>65$ & & & & & $1.2(0.40-3.4)$ & 0.793 & $0.89(0.31-2.6)$ & 0.836 \\
\hline \multicolumn{9}{|c|}{ Performance status (WHO) } \\
\hline 0 & 1.0 & 0.523 & 1.0 & 0.473 & $\mathrm{NI}$ & & 1.0 & 0.022 \\
\hline 1 & $0.73(0.24-2.2)$ & 0.576 & $0.61(0.23-1.6)$ & 0.315 & & & $1.2(0.52-2.9)$ & 0.640 \\
\hline $2+3+4$ & $1.9(0.31-12)$ & 0.483 & $1.4(0.25-7.6)$ & 0.722 & & & $7.7(1.7-34)$ & 0.008 \\
\hline \multicolumn{9}{|l|}{ Site } \\
\hline $\mathrm{SN}$ & $2.1(0.52-8.7)$ & 0.298 & $2.1(0.64-7.4)$ & 0.216 & $\mathrm{NI}$ & & $\mathrm{NI}$ & \\
\hline OC-OP & 1.0 & & 1.0 & & & & & \\
\hline \multicolumn{9}{|l|}{ Pigmented lesion } \\
\hline Yes & $\mathrm{NI}$ & & $\mathrm{NI}$ & & 1.0 & & $\mathrm{NI}$ & \\
\hline No & & & & & $1.2(0.40-3.4)$ & 0.779 & & \\
\hline \multicolumn{9}{|c|}{ Treatment modality } \\
\hline Surgery & $2.2(0.42-12)$ & 0.355 & $4.7(0.98-22)$ & 0.054 & $\mathrm{NI}$ & & $1.0(0.46-2.2)$ & 0.979 \\
\hline RT & $11(2.1-63)$ & 0.005 & $16(3.0-80)$ & 0.001 & & & $2.0(0.73-5.5)$ & 0.175 \\
\hline surgery+PORT & 1.0 & 0.005 & 1.0 & 0.002 & & & 1.0 & 0.303 \\
\hline \multicolumn{9}{|l|}{ Systemic therapy } \\
\hline Yes & $\mathrm{NI}$ & & $\mathrm{NI}$ & & 1.0 & & 1.0 & \\
\hline No & & & & & $2.6(0.62-11)$ & 0.193 & $3.1(0.92-10)$ & 0.068 \\
\hline
\end{tabular}

${ }^{\mathrm{a}}$ Factors with no statistical significance in univariate analysis were included if deemed clinically relevant

$\mathrm{NI}$ not included in multivariate analysis, LC Local control, LRC Locoregional control, DMFS Distant metastasis-free survival, OS Overall survival, WHO World Health Organization, SN Sinonasal, OC-OP Oral cavity/oropharynx, RT Radiotherapy, PORT Postoperative radiotherapy

(endoscopic -6 , open -3 ) with clear margins achieved in all cases. One patient had unilateral elective dissection of regions I-II and in another patient bilateral dissection was done due to clinically evident CLN metastases (regions I-V). PORT was implemented in two cases. Disease recurred in six patients: two of them had isolated local recurrence 41 and 51 months after the first treatment and were successfully salvaged by additional surgery with PORT in one case. The other four patients had more than one failure. Six of the longterm survivors eventually died of MMHN.

\section{Discussion}

In the present study, surgery followed by PORT resulted in the most favorable LRC compared to surgery alone or $\mathrm{RT}$ alone. In view of no survival advantage of combined therapy observed in our patients and significant lack in the use of comprehensive pre- and post-RT imaging (CT/MR), we recommend PORT only to selected patients at increased risk of recurrence in surgical field.

The incidence of MMHN in Slovenia (1.1 per million per year) is in line with the published data from Europe and the USA and does not appear to be rising $[2-4,10]$. Also, other epidemiological data are within the frames of comparable preceding reports [13-16]. MMHN's predilection to occur in the nasal cavity and paranasal sinuses compared to the oral cavity and oropharynx was confirmed in the present series, yet no explanation of this difference has thus far been validated [8]. In the present series, the mode of primary treatment did indeed affect the course of the disease. The most favorable outcome in terms of LC and LRC was achieved by combining surgery and RT (Fig. 1, Table 4), although with no survival advantage observed. Therefore, potential toxicity of high-dose RT should always be taken into account and such treatment offered only to selected patients where LRC outweighs the risks of serious adverse effects.

The efficacy of RT in MMHN has been thus far analyzed in a number of series and it seems that both definitive RT and PORT improve local control [17]. In particular, high-linear energy transfer radiation appears to be comparable to surgery in maintaining local control in MMHN [18]. Both positive and close margins, difficult-to-access $\mathrm{SN}$ sites with a high probability of residual disease as well as multiple positive nodes and extracapsular tumor spread warrant adjuvant irradiation [17]. In our patients photon/electron RT to the site of the primary tumor was employed in 27 (56 \%) curative-intent 
Table 5 Mucosal melanoma of the head and neck: a review of the recent literature series (with $\geq 50$ patients \& utilizing radiotherapy)

\begin{tabular}{|c|c|c|c|c|c|c|c|c|c|}
\hline Author & Setting, country & $\begin{array}{l}\text { Period of } \\
\text { diagnosis }\end{array}$ & $\begin{array}{l}\text { No. of } \\
\text { patients }\end{array}$ & $\begin{array}{l}\text { Age } \\
\text { Median/Mean* } \\
\text { (range) }\end{array}$ & $\begin{array}{l}\text { Primary tumor } \\
\text { site (\%) }\end{array}$ & TNM stage (\%) & $\begin{array}{l}\text { Treatment } \\
\text { modality (\%) }\end{array}$ & $\begin{array}{l}\text { OS } \\
\text { (at } 5 \text { years, \%) }\end{array}$ & $\begin{array}{l}\text { DSS, } \\
\text { (at } 5 \text { years, \%) }\end{array}$ \\
\hline \multirow[t]{4}{*}{ Gal et al., 2011 [29] } & \multirow{4}{*}{$\begin{array}{l}\text { Population-based } \\
(26 \%) \text {, USA }\end{array}$} & \multirow[t]{4}{*}{$2000-2007$} & \multirow[t]{4}{*}{304} & \multirow[t]{4}{*}{$71.2^{*}$} & \multirow[t]{4}{*}{ SN, all } & III, 32.2 & $S, 43.1$ & \multirow[t]{4}{*}{24.2} & \multirow[t]{4}{*}{ NR } \\
\hline & & & & & & IVA, 25.3 & SRT, 38.5 & & \\
\hline & & & & & & IVB, 11.2 & RT, 7.6 & & \\
\hline & & & & & & IVC, 12.2 & None/Unknown, 10.9 & & \\
\hline \multirow[t]{4}{*}{ Jangard et al., 2013 [13] } & \multirow{4}{*}{$\begin{array}{l}\text { Population-based } \\
(96 \%) \text {, Sweden }\end{array}$} & \multirow[t]{4}{*}{ 1960-2000 } & \multirow[t]{4}{*}{186} & \multirow[t]{4}{*}{$72(31-93)$} & \multirow[t]{4}{*}{ SN, all } & ।, 83.9 & S, 53.1 & \multirow[t]{4}{*}{ NR } & \multirow[t]{4}{*}{20.4} \\
\hline & & & & & & $\|, 2.2$ & SRT, 32 & & \\
\hline & & & & & & III, 4.3, & SRTSTh, 2.7 & & \\
\hline & & & & & & Unknown, 9.7 & Palliative, 12.2 & & \\
\hline \multirow[t]{3}{*}{ Benlyazid et al., 2010 [30] } & \multirow{3}{*}{$\begin{array}{l}\text { Multi-institutional, } \\
\text { France }\end{array}$} & \multirow[t]{3}{*}{ 1980-2008 } & \multirow[t]{3}{*}{160} & $67.0(30-93)$ & SN, 90.6 & I, 96.3 & $S, 51.3$ & 37.5 & NR \\
\hline & & & & & OC, 7.5 & II, 3.8 & SRT, 48.8 & & \\
\hline & & & & & Other, 1.9 & & & & \\
\hline Lund et al., 2012 [27] & Single institution, UK & 1963-2010 & 115 & $65.9^{*}(15-91)$ & SN, all & ।, 87.8 & S, 55.7 & 28 & NR \\
\hline & & & & & & $\begin{array}{l}\text { II, } 8.7 \text { Unknown, } \\
3.5\end{array}$ & SRT, 44.3 & & \\
\hline Shiga et al., 2012 [31] & $\begin{array}{l}\text { Multi-institutional, } \\
\text { Japan }\end{array}$ & 1998-2007 & 94 & $68.4^{*}(37-96)$ & SN, 78.7 & I, 16.0 & S, 9.6 & $\mathrm{~S}+\mathrm{STh} / \mathrm{RT}, 38.6$ & NR \\
\hline & & & & & OC-OP, 15.6 & ॥, 28.7 & RT, 9.6 & RT+/-STh, 29.9 & \\
\hline & & & & & $\begin{array}{l}\text { Unknown primary, } \\
\text { 3.2 External ear, } 2.1\end{array}$ & III, 9.6 & STh, 7.4 & & \\
\hline & & & & & & IVA, 31.9 & $\mathrm{~S}+\mathrm{STh} / \mathrm{RT}, 52.1$ & & \\
\hline & & & & & & IVB, 3.2 & RT+/-STh, 19.1 & & \\
\hline & & & & & & IVC, 10.6 & None, 2.1 & & \\
\hline Meng et al., 2014 [32] & Single institution, & $2000-2010$ & 69 & $65.9^{*}(28-89)$ & $\mathrm{SN}$, all & III, 53.6 & S, 39.1 & $S, 31.6$ & NR \\
\hline & China & & & & & IVA, 39.1 & SRT, 34.8 & SRT, 55 & \\
\hline & & & & & & IVB, 7.2 & SRTSTh, 26.1 & SRTSTh, 32.1 & \\
\hline Sun et al., 2014 [33] & Single institution, & 1976-2005 & 68 & $55(2-79)$ & $\mathrm{SN}$, all & III, 52.9 & S, 27.7 & 29.7 & NR \\
\hline & & & & & & IVA, 35.3 & $\mathrm{RT}, 6.2$ & & \\
\hline & & & & & & IVB, 5.9 & STh, 12.3 & & \\
\hline & & & & & & IVC, 5.9 & SRT, 20.0 & & \\
\hline & & & & & & & $S+S T h, 29.2$ & & \\
\hline & & & & & & & $\mathrm{RT}+\mathrm{STh}, 3.1$ & & \\
\hline & & & & & & & SRTSTh, 1.5 & & \\
\hline
\end{tabular}


Table 5 Mucosal melanoma of the head and neck: a review of the recent literature series (with $\geq 50$ patients \& utilizing radiotherapy) (Continued)

\begin{tabular}{|c|c|c|c|c|c|c|c|c|c|}
\hline \multirow[t]{4}{*}{ Douglas et al., 2010 [34] } & \multirow[t]{4}{*}{ Single institution, UK } & \multirow[t]{4}{*}{$1965-2001$} & \multirow[t]{4}{*}{68} & \multirow[t]{4}{*}{$63(29-86)$} & SN, 65 & 1,80 & S, 27 & \multirow[t]{4}{*}{22} & \multirow[t]{4}{*}{32} \\
\hline & & & & & OC, 19 & $\|, 19$ & RT, 46 & & \\
\hline & & & & & \multirow[t]{2}{*}{ Other, 16} & \multirow[t]{2}{*}{ III, 1} & SRT, 7 & & \\
\hline & & & & & & & Palliative, 20 & & \\
\hline \multirow[t]{7}{*}{ Demizu et al., 2014 [35] } & \multirow{7}{*}{$\begin{array}{l}\text { Single institution, } \\
\text { Japan }\end{array}$} & \multirow[t]{7}{*}{ 2003-2011 } & \multirow[t]{7}{*}{62} & \multirow[t]{7}{*}{70.5 (33-89) } & SN, 90.3 & $\mathrm{~T} 1,27$ & RT, all & At 1 year, 93 & \multirow[t]{7}{*}{ NR } \\
\hline & & & & & \multirow[t]{6}{*}{ OC, 9.7} & $\mathrm{~T} 2,31$ & - protons, 53.2 & \multirow[t]{6}{*}{ At 2 years, 61} & \\
\hline & & & & & & $\mathrm{T} 3,31$ & - carbon ion, 46.8 & & \\
\hline & & & & & & $\mathrm{T} 4,11$ & Prior treatment: & & \\
\hline & & & & & & & $S, 11.3$ & & \\
\hline & & & & & & & STh, 8.1 & & \\
\hline & & & & & & & $S+S T h, 3.2$ & & \\
\hline \multirow[t]{3}{*}{ Moreno et al., 2010 [19] } & \multirow{3}{*}{$\begin{array}{l}\text { Single institution, } \\
\text { USA }\end{array}$} & \multirow[t]{3}{*}{ 1993-2004 } & \multirow[t]{3}{*}{58} & \multirow[t]{3}{*}{$63.4(38-93)$} & \multirow[t]{3}{*}{ SN, all } & ।, 87.9 & $S, 43.1$ & \multirow[t]{3}{*}{38.7} & \multirow[t]{3}{*}{18.4} \\
\hline & & & & & & $\|, 6.9$ & SRT, 53.4 & & \\
\hline & & & & & & III, 5.2 & RT, 3.4 & & \\
\hline \multirow[t]{4}{*}{ Shuman et al., 2011 [28] } & \multirow{4}{*}{$\begin{array}{l}\text { Single institution, } \\
\text { USA }\end{array}$} & \multirow[t]{4}{*}{ 1992-2009 } & \multirow[t]{4}{*}{52} & $66^{*}$ & OC, 31 & ।, 25.0 & $S, 69.2$ & 38 & 22 \\
\hline & & & & & SN, 69 & ॥l, 34.6 & SRT, 19.2 & & \\
\hline & & & & & & III, 11.5 & Palliative RT, 9.6 & & \\
\hline & & & & & & IV, 28.8 & & & \\
\hline Sun et al., 2012 [36] & Single institution, & $1976-2005$ & 51 & $55(31-75)$ & OC, all & III, 23.5 & S, 76.5 & 20.7 & NR \\
\hline & China & & & & & IVA, 34 & SRT, 3.9 & & \\
\hline & & & & & & IVB, 4 & STh, 11.8 & & \\
\hline & & & & & & IVC, 1 & None, 7.8 & & \\
\hline Koivunen et al., 2012 [37] & Multi-institutional, & 1990-2004 & 50 & $70^{*}(46-93)$ & SN, all & III, 36 & $S, 66.0$ & 27 & 48 \\
\hline & & & & & & IVA, 42 & SRT, 14.0 & & \\
\hline & & & & & & IVB, 20 & RT, 14.0 & & \\
\hline & & & & & & IVC, 2 & & & \\
\hline Current series, 2016 & Population-based, & 1986-2013 & 61 & $75.5(25-91)$ & SN, 72 & III, 34 & Curative intent & Whole cohort, 18 & Curative intent, 25 \\
\hline & Slovenia & & & & OC-OP, 26 & IVA, 49 & $(N=48):$ & Curative intent, 24 & \\
\hline & & & & & Middle ear, 1.6 & IVB, 12 & $S, 44$ & & \\
\hline & & & & & & IVC, 4.9 & SRT, 33 & & \\
\hline & & & & & & & RT, 23 & & \\
\hline
\end{tabular}

OS Overall survival, SN Sinonasal tract, S Surgery, SRT Surgery and postoperative radiotherapy, RT Radiotherapy, NR Not reported, SRTSTh Surgery with postoperative radiotherapy and systemic therapy, OC Oral cavity, OC-OP Oral cavity and oropharynx, STh Systemic therapy

*Mean age 
patients with the neck irradiated in 10 of these patients to the median EQD2 of 68.8 Gy (definitive setting) and 60.0 Gy (PORT setting). The herein confirmed positive impact of high dose PORT (>54 Gy) on LRC has been previously suggested by Moreno et al. [19] In regard to fractionation pattern, the optimal schedule is unclear: conventional fractionation is widely accepted (it was used in $18 / 27$ of our patients) whereas clinical utility of hypofractionation, despite being radiobiologically superior to melanoma cells, seems to be limited in the head and neck region by proximity of important normal tissues sensitive to higher fraction doses [20].

Considering the low rate of spread to the CLN, we advocate elective neck dissection only for selected patients with a high local disease burden or with a primary tumor located in or extending to the oral cavity or oropharynx. In the present series, of $12 / 61$ patients presenting with clinically positive CLN, six had neck dissection ( $\mathrm{pN}+$ disease confirmed in all cases) and two received definitive neck irradiation. Besides these, two patients with pT4a tumors and without clinically positive CLN were treated with neck dissection as well, both being classified as pN0. Overall, of 48 patients treated with curative intent $17 \%$ later relapsed in the CLN. However, this figure must be interpreted with caution, because as much as $48 \%$ of the patients had only clinical examination of the neck performed during primary diagnostics. In the literature, there has been much controversy over elective treatment of CLN. The latter is supported by some authors $[15,21]$ while others oppose elective neck dissection in MMHN because of low rates of positive $\mathrm{CNL}$ and regional recurrences, proposing only a wait-and-see policy [22]. An appealing approach to clarify the need for elective neck dissection in MMHN patients is sentinel lymph node biopsy, which is an already well established diagnostic tool in cutaneous malignant melanoma. As only case reports on this subject have been published so far [23], further research is needed to determine its value in diagnostic algorithms for MMHN.

A combination of immunotherapy and chemotherapy (biochemotherapy) has previously showed considerable response rates and favorable effect on progression-free interval but with no impact on OS [24]. Our data from multivariate analysis, controlled for age, PS WHO and treatment modality, confirm the lack of effect of systemic treatment on survival. However, new targeted drugs are constantly being developed and their effect on disease course seems more promising. Taking into account results from cutaneous melanoma studies, the minority of MMHN patients with driver mutations of oncogenes could benefit from KIT and BRAF inhibitors $[25,26]$. The aggressive behavior of MMHN presents a great challenge to clinicians. Even in the era of advanced diagnostic and treatment options prognosis remains dismal and little progress in the outcome of these patients was observed. In 1998 Chang et al. reported on 212 MMHNs, diagnosed between 1985 and 1989, with a 5 -year overall survival rate of $31.7 \%$ which is not notably worse than most favorable results reported in the more recent series (Table 5) [3, 13, 19, 27-37]. These results suggest that at least a temporary plateau has been reached concerning survival. The herein presented results of multivariate analyses of survival possibly reflect this finding, as only performance status was found to be an independent prognosticator of OS. More advanced surgical and irradiation techniques used in more recent series probably resulted in improved treatment-related toxicity profile, contributing to less detrimental effect on post-treatment quality of life [32]. Nine patients in the present series who survived more than 5 years (3/9 lived more than 10 years) after diagnosing MMHN confirm the potential of achieving long survival times in MMHN. The retrospective nature of the present and previously published MMHN series is inherent to rare cancer studies. This results in notable treatment selection bias which in turn hampers analyses of prognostic factors. Furthermore, the majority of MMHN series are single- or multi-institutional, leading to possible referral bias. In contrast, the present series is a populationbased study and as such offers to fill this potential data gap. In addition, we performed controlled, multivariate analyses of prognostic factors, further contributing to the quality of the presented results.

\section{Conclusions}

MMHN is a rare cancer with a stable incidence of far below two cases per million. For this reason, unbiased data on the optimal treatment is lacking. However, MMHN's propensity to recur even after radical surgical treatment is well known and this dictates the need for aggressive adjuvant treatment. The results presented herein support the use of high-dose PORT in selected patients in whom LRC is deemed worth the side effects. The roles of elective treatment of the CLN and of systemic treatment remain to be elucidated.

\footnotetext{
Abbreviations

Cl: Confidence interval; CLN: Cervical lymph nodes; CT: Computer tomography; DMFS: Distant metastasis-free survival; $\mathrm{EQD}_{2}$ : Equivalent doses in 2-Gy fractions; HR: Hazard ratio; LC: Local control; LRC: Locoregional control; MMHN: Mucosal melanoma of the head and neck; MRI: Magnetic resonance imaging; N: Number of patients; NA: Not applicable; NI: Not included; NR: Not reported; OC-OP: Oral cavity and oropharynx; OS: Overall survival; PET: Positron emission tomography; PORT: Postoperative radiotherapy; RC: Regional control; SN: Sinonasal tract; SRTSTh: Surgery with postoperative radiotherapy and systemic therapy; STh: Systemic therapy; US: Ultrasonography; WHO PS: World Health Organization performance status
} 


\section{Funding}

This research received no specific grant from any funding agency in the public, commercial, or not-for-profit sectors.

\section{Availability of data and materials}

The datasets analyzed during the current study are available from the corresponding author on reasonable request.

\section{Authors' contributions}

Study concepts: GP, JB-H, PS. Study design: GP, PS. Data acquisition: all authors. Quality control of data: GP, PS. Data analysis and interpretation: GP, PS. Statistical analysis: GP. Manuscript preparation: all authors. Manuscript editing: PS. Manuscript review: GP, PS. All authors read and approved the final manuscript.

\section{Competing interests}

The authors declare that they have no competing interests.

\section{Consent for publication}

The Protocol Review Board and Ethics Committee of the Institute of Oncology approved the study, which was conducted in accordance with the ethical standards laid down in an appropriate version of the 1964 Declaration of Helsinki. The need for consent was waived by the Institutional Review Board and Ethics Committee of the Institute of Oncology Ljubljana.

\section{Ethics approval and consent to participate}

The study protocol was approved by the Protocol Review Board and Ethics Committee of the Institute of Oncology Ljubljana (ERID-KESOPKR/47). All patients gave consent for using their data for study purposes at the start of their treatment. For retrospective studies a written consent is deemed unnecessary according to national regulations.

\section{Author details}

'Department of Radiation Oncology, Institute of Oncology, Ljubljana, Slovenia. ${ }^{2}$ University Department of Otorhinolaryngology and Cervicofacial Surgery, University Clinical Center, Ljubljana, Slovenia. ${ }^{3}$ Department of Otorhinolaryngology, Cervical and Maxillofacial Surgery, University Clinical Center, Maribor, Slovenia. ${ }^{4}$ Department of Maxillofacial and Oral Surgery, University Clinical Center, Ljubljana, Slovenia. ${ }^{5}$ Faculty of Medicine, University of Ljubljana, Ljubljana, Slovenia.

Received: 28 February 2016 Accepted: 6 October 2016 Published online: 14 October 2016

\section{References}

1. Weber CO. Chirurgische Ehrfahrungen und Untersuchungen, nebst zahlreichen Beobachtungen aus der chirurgischen Klinik und dem Evangelischen Krankenhaus zu Bonn. Berlin: G Reimer; 1859.

2. Mallone S, De Vries E, Guzzo M. Descriptive epidemiology of malignant mucosal and uveal melanomas and adnexal skin carcinomas in Europe. Eur J Cancer. 2012;48:1167-75.

3. Chang AE, Karnell LH, Menck HR. The National Cancer Data Base report on cutaneous and noncutaneous melanoma: a summary of 84,836 cases from the past decade. The American College of Surgeons Commission on Cancer and the American Cancer Society. Cancer. 1998;83:1664-78.

4. McLaughlin CC, Wu XC, Jemal A, Martin HJ, Roche LM, Chen WW. Incidence of noncutaneous melanomas in the US. Cancer. 2005;103:1000-7.

5. Takagi M, Ishikawa G, Mori W. Primary malignant melanoma of the oral cavity in Japan. With special reference to mucosal melanosis. Cancer. 1974; 34:358-70.

6. Lewis MG, Martin JAM. Malignant melanoma of the nasal cavity in Ugandan Africans. Cancer. 1967;20:1699-705.

7. Dahl C, Guldberg P. The genome and epigenome of malignant melanoma. APMIS. 2007;115:1161-76.

8. López F, Rodrigo JP, Cardesa A, Triantafyllou A, Devaney KO, Mendenhall WM, et al. Update on primary head and neck mucosal melanoma. Head Neck. 2016; 38:147-55.

9. Thompson LD, Wieneke JA, Miettinen M. Sinonasal tract and nasopharyngeal melanomas: a clinicopathologic study of 115 cases with a proposed staging system. Am J Surg Pathol. 2003;27:594-611.
10. Zadnik V, Primic Žakelj M. SLORA: Slovenia and Cancer. Epidemiology and Cancer Registry. Istitute of Oncology Ljubljana. www.slora.si (Updated 2015 December 1; cited 2016 January 10).

11. Jones B, Dale RG, Deehan C, Hopkins KI, Morgan DA. The role of biologically effective dose (BED) in clinical oncology. Clin Oncol. 2001;13:71-81.

12. Peduzzi P, Concato J, Feinstein AR, Holford TR. Importance of events per independent variable in proportional hazards regression analysis. II. Accuracy and precision of regression estimates. J Clin Epidemiol. 1995;48: 1503-10.

13. Jangard M, Hansson J, Ragnarsson-Olding B. Primary sinonasal malignant melanoma: a nationwide study of the Swedish population, 1960-2000. Rhinology. 2013;51:22-30.

14. Jethanamest D, Vila PM, Sikora AG, Morris LG. Predictors of survival in mucosal melanoma of the head and neck. Ann Surg Oncol. 2011;18:2748-56.

15. Wu Y, Zhong Y, Li C, Song H, Guo W, Ren G. Neck dissection for oral mucosal melanoma: caution of nodular lesion. Oral Oncol. 2014;50:319-24.

16. Yii NW, Eisen T, Nicolson M, A'Hern R, Rhys-Evans P, Archer D. Mucosal malignant melanoma of the head and neck: the Marsden experience over half a century. Clin Oncol. 2003;15:199-204.

17. Krengli M, Jereczek-Fossa BA, Kaanders JH, Masini L, Beldi D, Orecchia R. What is the role of radiotherapy in the treatment of mucosal melanoma of the head and neck? Crit Rev Oncol Hematol. 2008;65:121-8.

18. Yanagi T, Mizoe JE, Hasegawa A, Takagi R, Bessho H, Onda T, et al. Mucosal malignant melanoma of the head and neck treated by carbon ion radiotherapy. Int J Radiat Oncol Biol Phys. 2009;74:15-20.

19. Moreno MA, Roberts DB, Kupferman ME, DeMonte F, El-Naggar AK, Williams $M$, et al. Mucosal melanoma of the nose and paranasal sinuses, a contemporary experience from the M. D. Anderson Cancer Center. Cancer. 2010;116:2215-23.

20. Thariat J, Poissonnet G, Marcy PY, Lattes L, Butori C, Guevara N, et al. Effect of surgical modality and hypofractionated split-course radiotherapy on local control and survival from sinonasal mucosal melanoma. Clin Oncol. 2011;23:579-86.

21. Yang X, Ren GX, Zhang CP, Zhou G, Hu Y, Yang W, et al. Neck dissection and post-operative chemotherapy with dimethyl triazeno imidazole carboxamide and cisplatin protocol are useful for oral mucosal melanoma. BMC Cancer. 2010;10:623.

22. Wang $X$, Wu H-M, Ren G-X, Tang J, Guo W. Primary oral mucosal melanoma: advocate a wait-and-see policy in the clinically NO patient. J Oral Maxillofac Surg. 2012;70:1192-8.

23. Postow MA, Hamid O, Carvajal RD. Mucosal melanoma: pathogenesis, clinical behavior, and management. Curr Oncol Rep. 2012;14:441-8.

24. Bartell HL, Bedikian AY, Papadopoulos NE, Dett TK, Ballo MT, Myers JN, et al. Biochemotherapy in patients with advanced head and neck mucosal melanoma. Head Neck. 2008;30:1592-8.

25. Lyu J, Wu Y, Li C, Wang R, Song H, Ren G, et al. Mutation scanning of BRAF, NRAS, KIT, and GNAQ/GNA11 in oral mucosal melanoma: a study of 57 cases. J Oral Pathol Med. 2016;45:295-301.

26. Zebary A, Jangard M, Omholt K, Ragnarsson-Olding B, Hansson J. KIT, NRAS and BRAF mutations in sinonasal mucosal melanoma: a study of 56 cases. Br J Cancer. 2013;109:559-64.

27. Lund VJ, Chisholm EJ, Howard DJ, Wei WI. Sinonasal malignant melanoma: an analysis of 115 cases assessing outcomes of surgery, postoperative radiotherapy and endoscopic resection. Rhinology. 2012;50:203-10.

28. Shuman AG, Light E, Olsen SH, Pynnonen MA, Taylor JM, Johnson TM, et al. Mucosal melanoma of the head and neck: predictors of prognosis. Arch Otolaryngol Head Neck Surg. 2011;137:331-7.

29. Gal TJ, Silver N, Huang B. Demographics and treatment trends in sinonasal mucosal melanoma. Laryngoscope. 2011;121:2026-33.

30. Benlyazid A, Thariat J, Temam S, Malard O, Florescu C, Choussy O, et al. Postoperative radiotherapy in head and neck mucosal melanoma: a GETTEC study. Arch Otolaryngol Head Neck Surg. 2010;136:1219-25.

31. Shiga K, Ogawa T, Kobayashi T, Ueda S, Kondo A, Nanba A, et al. Malignant melanoma of the head and neck: a multi-institutional retrospective analysis of cases in northern Japan. Head Neck. 2012;34:1537-41.

32. Meng XJ, Ao HF, Huang WT, Chen F, Sun XC, Wang JJ, et al. Impact of different surgical and postoperative adjuvant treatment modalities on survival of sinonasal malignant melanoma. BMC Cancer. 2014;14:608.

33. Sun $C Z$, Li QL, Hu ZD, Jiang YE, Song M, Yang AK. Treatment and prognosis in sinonasal mucosal melanoma: a retrospective analysis of 65 patients from a single cancer center. Head Neck. 2014;36:675-81. 
34. Douglas CM, Malik T, Swindell R, Lorrigan P, Slevin NJ, Homer JJ. Mucosal melanoma of the head and neck: radiotherapy or surgery? J Otolaryngol. 2010;39:385-92.

35. Demizu Y, Fujii O, Terashima K, Mima M, Hashimoto N, Niwa Y, et al. Particle therapy for mucosal melanoma of the head and neck: a single-institution retrospective comparison of proton and carbon ion therapy. Strahlenther Onkol. 2014;190:186-91.

36. Sun $\mathrm{CZ}$, Chen YF, Jiang YE, Hu ZD, Yang AK, Song M. Treatment and prognosis of oral mucosal melanoma. Oral Oncol. 2012;48:647-52.

37. Koivunen P, Back L, Pukkila M, Laranne J, Kinnunen I, Grenman R, et al. Accuracy of the current TNM classification in predicting survival in patients with sinonasal mucosal melanoma. Laryngoscope. 2012;122:1734-8.

Submit your next manuscript to BioMed Central and we will help you at every step:

- We accept pre-submission inquiries

- Our selector tool helps you to find the most relevant journal

- We provide round the clock customer support

- Convenient online submission

- Thorough peer review

- Inclusion in PubMed and all major indexing services

- Maximum visibility for your research

Submit your manuscript at www.biomedcentral.com/submit 